\title{
Direct controls for wind turbine with PMSG used on the real wind profile of Essaouira-Morocco city
}

\author{
Dalila Hammoumi ${ }^{1}$, Chakib El Bekkali ${ }^{2}$, Mohammed Karim $^{3}$, Mohammed Taoussi ${ }^{4}$, Najib El Ouanjli ${ }^{5}$, \\ Badre Bossoufi ${ }^{6}$ \\ 1,2,3,4,6 Laboratory of Systems Integration and Advanced Technologies, Faculty of Sciences Dhar El Mahraz, \\ Sidi Mohamed Ben Abdellah University Fez, Morocco \\ ${ }^{5}$ Laboratory of Production Engineering, Energy and Sustainable Development, Higher School of Technology, \\ Sidi Mohamed Ben Abdellah University Fez, Morocco
}

\begin{tabular}{l} 
Article Info \\
\hline Article history: \\
Received Feb 20, 2019 \\
Revised Jun 3, 2019 \\
Accepted Jul 5, 2019 \\
\hline Keywords: \\
Direct power control \\
Direct torque control \\
Essaouira-Morroco \\
Permanent magnet synchronous \\
generator
\end{tabular}

\section{Article Info}

Article history:

Received Feb 20, 2019

Revised Jun 3, 2019

Accepted Jul 5, 2019 generator

\section{Corresponding Author:}

Dalila Hammoumi,

LISTA laboratory, Faculty of Sciences Dhar El Mahraz,

Sidi Mohamed Ben Abdellah University Fez, Morocco

Email: dalila.hammoumi@usmba.ac.ma

\begin{abstract}
This article presents the use of a permanent magnet synchronous generator (PMSG) for the wind energy production and electrical energy injection produced into an electrical grid. The objective is to perform modeling and direct control of the Wind Energy conversion System (WECS), taking into account the problems of wind speed variations and generator maintenance. The direct torque control (DTC) is applied to the machine-side converter and direct power control (DPC) is applied to the grid-side converter. The performance of WECS is tested in MATLAB / SIMULINK environment simulation with a real wind profile of Essaouira-Morroco city. The simulation results obtained show that the proposed direct controls provide high performance in terms of setpoint tracking, speed, stability and power quality.
\end{abstract}

Copyright () 2019 Institute of Advanced Engineering and Science. All rights reserved.

\section{INTRODUCTION}

Energy conversion chains associated with wind power often use a permanent magnet synchronous generator (PMSG) due to self-excitation, which allows operation with high power factor and high efficiency [1]. Indeed the synchronous machine is characterized by high volume torque as well as a low inertia and inductance [2], which gives it high performance compared to the asynchronous generator, a high efficiency and better controllability [3]. However the control of this machine remains complex because of the decoupling between the electromagnetic torque and flux.

The vector control is one of the strategies that ensure a decoupling between the magnitudes of the machine [4]. This technique was proposed by Blaschke [5-6], it is characterized by a good performance and fast dynamic response. However, this control is not effective when the system is non-linear undergoes internal and external disturbances [7].

Therefore, in this work, the direct controls strategies applied to PMSG-Converters are proposed to improve the machine performance and guarantee the quality power injected into the grid. The Direct Torque control (DTC) is developed to control the machine-side converter (MSC). While, the direct power control (DPC) is used to control the grid-side converter (GSC). The main contributions of this work are:

a. Development of a direct control that provides better performances.

b. The decoupling of the electromagnetic torque and flux is assured.

c. Applying a real wind profile of Essaouira-Morroco city to wind energy conversion system. 
This paper is structured as follows: section 2 present the modeling of wind energy conversion system. Section 3 develops the direct controls strategies, DTC is applied to PMSG-side converter and DPC is applied to grid-side converter. The simulation results in Matlab/Simulink are presented and discussed in section 4. Finally, conclusions and suggestions for future works are given in Section 5.

\section{MODELING OF WIND ENERGY CONVERSION SYSTEM}

The wind energy conversion system consists of a variable speed turbine coupled directly to a permanent magnet synchronous generator, connected to the electrical grid via three-phase static converters [8]. Figure 1 illustrates the Synoptic diagram of the studied system.

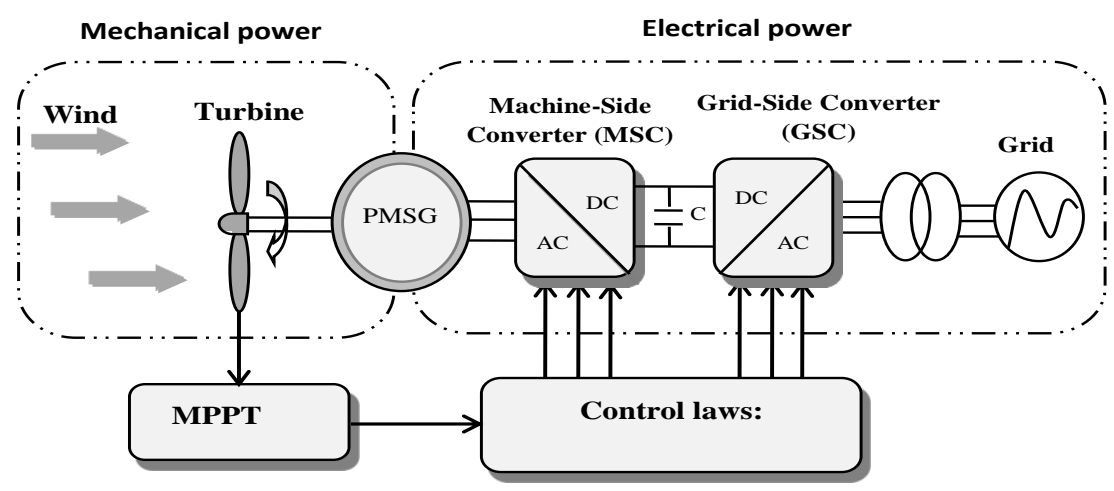

Figure 1. Synoptic diagram of the studied system

\subsection{Wind turbine modeling}

The wind turbine is a device whose role is the transformation of kinetic energy into mechanical energy [9].

The wind power $\mathrm{Pv}$ that passes through the active surface $\mathrm{S}$ of the wind turbine is given by [10]:

$$
P_{v}=\frac{1}{2} \rho \pi R^{2} V_{v}^{3}
$$

The mechanical power is linked to the kinetic power by the following equation:

$$
P_{e o l}=C_{p} P v=\frac{1}{2} C_{p} \rho \pi R^{2} V_{v}^{3}
$$

Thus, the expression of the corresponding wind torque is given by:

$$
T_{e o l}=\frac{P_{e o l}}{\Omega}=\frac{1}{2 \Omega} \cdot C_{p} \cdot \rho \cdot \pi R^{2} \cdot V_{v}^{3}
$$

Figure 2 illustrates the characteristics of power coefficient $\mathrm{Cp}$ as a function of $\lambda$ and $\beta$. The power coefficient $\mathrm{Cp}$ depends on the pitch angle $\beta$ and the tip-speed ratio $\lambda$. It is given by the following equation [11-12]:

$$
C_{p}(\lambda, \beta)=0.5176 .\left(\frac{116}{\lambda+0.08 \beta}-\frac{4.06}{\beta^{3}+1}-0.4 \beta-5\right) e^{-\frac{21}{A}}++0.0068 \lambda
$$

With:

$$
\lambda=\frac{\Omega \cdot R}{V v}
$$

From the Figure 2, the maximum power coefficient $(\mathrm{Cp}-\mathrm{max} \approx 0.5506)$ is characterized by optimal speed ratio $(\lambda \mathrm{opt}=12)$ for pitch angle $\beta$ equal to zero. 


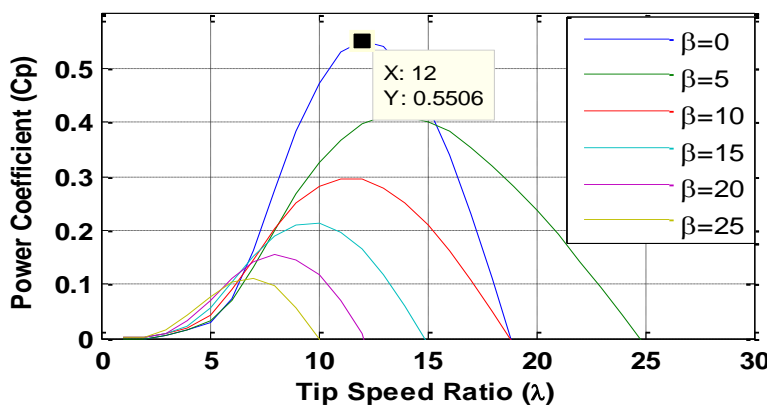

Figure 2. Power coefficient

\subsection{Modeling of the Permanent Magnet Synchronous Generator}

Once the mechanical modeling was done, we went to the generator and our choice fell on the permanent magnet synchronous generator. We consider the synchronous machine with smooth poles $(\mathrm{L} \alpha \mathrm{s}=\mathrm{L} \beta \mathrm{s}=\mathrm{Ls})[13]$.

$$
\left\{\begin{array}{c}
V_{s \alpha}=-R_{s} i_{s \alpha}-L_{s} \frac{d i_{s \alpha}}{d t}+L_{s} \omega i_{s \beta} \\
V_{s \beta}=-R_{s} i_{s \beta}-L_{s} \frac{d i_{s \beta}}{d t}-L_{s} \omega i_{s \alpha}+\psi_{f} \omega
\end{array}\right.
$$

The mechanical equation of the system is expressed by:

$$
T_{e o l}-T_{e m}=J \frac{d \Omega}{d t}+f \Omega
$$

The expression of the electromagnetic torque is given by:

$$
\left\{\begin{array}{c}
T_{e m}=\frac{3}{2} p i_{s \beta} \psi_{f} \\
\omega=p \Omega
\end{array}\right.
$$

\subsection{Speed control of the generator}

To control speed of the PSMG, the optimal speed reference expressed by (4) was used where $\lambda$ opt is the optimal ratio between turbine speed and wind speed. This reference is obtained from the Maximum Power Point Tracking technique (MPPT). The speed control strategy of the PMSG is illustrated in Figure 3.

$$
\Omega_{r e f}=\frac{\lambda_{o p t} \cdot v}{R_{t}}
$$

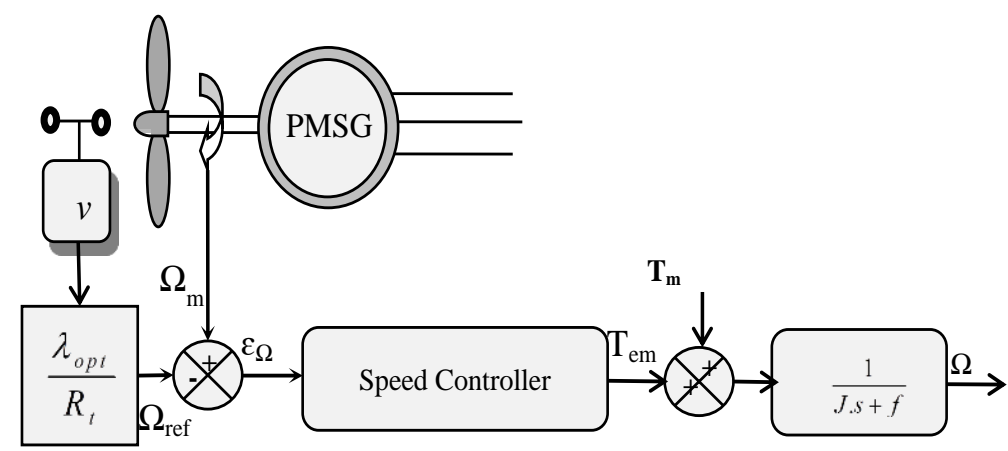

Figure 3. Speed control strategy 


\section{DIRECT CONTROL OF THE PERMANENT MAGNET SYNCHRONOUS GENERATOR}

Direct Controls (DC) are control techniques that provide a simple decoupling to implement between different systems parameters. The DC of a permanent magnet synchronous machine is based on the direct determination of the control sequence applied to the switches of a voltage inverter, which determines its state [14]. This choice is generally based on the use of hysteresis comparators whose function is to control the system state, namely the flux amplitude, electromagnetic torque, DC bus voltage, active power and reactive power [15].

The power converter used is conventional two-level voltage inverter conventional in Figure 4 . The latter allows reaching eight distinct positions in the phase plane, corresponding to the eight voltage sequences of the inverter [16-17].

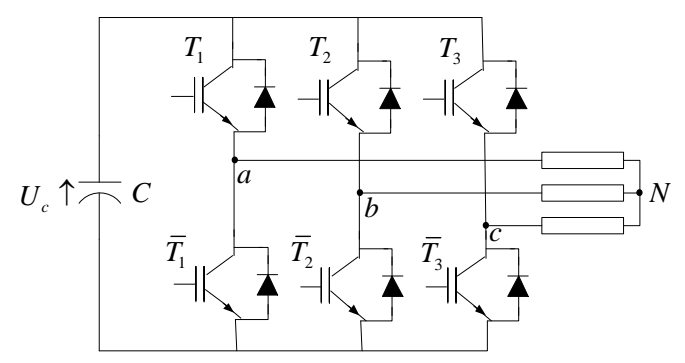

Figure 4. General structure of the voltage inverter

The mathematical model of the three-phase inverter is represented by the following matrix [18]:

$$
\left(\begin{array}{l}
V_{a} \\
V_{b} \\
V_{c}
\end{array}\right)=\frac{1}{3} U_{0} \cdot\left(\begin{array}{ccc}
2 & -1 & -1 \\
-1 & 2 & -1 \\
-1 & -1 & 2
\end{array}\right) \cdot\left(\begin{array}{l}
S_{a} \\
S_{b} \\
S_{c}
\end{array}\right)
$$

The voltage vector Vs is defined as the combination of the three switching states:

$$
\bar{V}_{s}=V_{s \alpha}+j \cdot V_{s \beta}=\sqrt{\frac{2}{3}} U_{0}\left(S_{a}+S_{b} e^{j_{3}^{2 \pi}}+S_{c} e^{j_{3}^{4 \pi}}\right)
$$

a. $S_{i(i=a, b, c)}=1$ if the low switch is closed and the high switch is open.

b. $S_{i(i=a, b, c)}=0$ if the low switch is open and the high switch is closed

The combinations of the three magnitudes $(\mathrm{Sa}, \mathrm{Sb}, \mathrm{Sc})$ make it possible to generate eight positions 23 of the voltage vector Vs of which 6 are active (have the same module equal to $\sqrt{\frac{2}{3}} U_{0}$ ) and two null vectors. The extremities of these six vectors defining the vertices of a regular hexagon since two successive vectors make between them an angle of $30^{\circ}$ called sector or zone. The eight voltage vectors are represented in the plan $(\alpha-\beta)$ by Figure 5 .

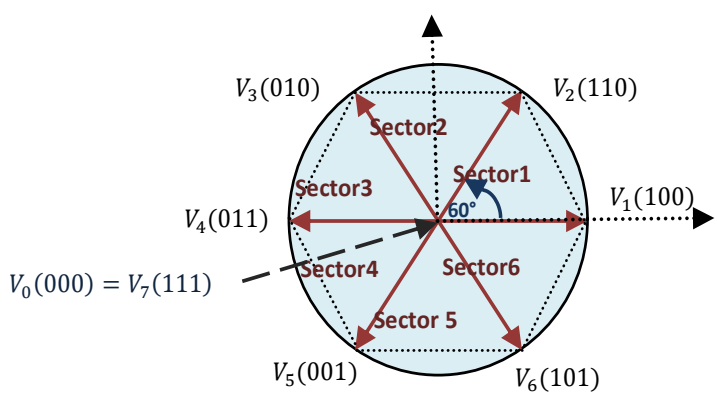

Figure 5. Elaboration of the stator voltage vector 
The main idea of Direct Control is demonstrated by its application to the wind system using the PMSG. We note that power generation and control do not only depend on the PMSG, but also on the manner in which the voltage converters are controlled.

The machine-side converter (MSC) consists of adjusting the electromagnetic torque and the flux. For this, it is necessary to apply the direct torque control (DTC). The grid-side converter (GSC) consists of controlling the active and reactive power of the machine to the grid. For this, it is necessary to apply the direct power control (DPC).

\subsection{Application of DTC to the Machine-Side Converter}

DTC is a control technique that provides simple decoupling of flux and torque. It is a question of maintaining the magnitudes of stator flux and the electromagnetic torque inside these bands of hysteresis. The principle of the DTC is the torque direct regulation of the permanent magnet synchronous machine by the application of the various inverter voltage vectors, which determines its state. The two control variables are the stator flux and electromagnetic torque [19-20]. This command is characterized by a high performance, good robustness against parametric variations of the generator and its simplicity of implementation [21-22]. The diagram of the DTC applied to PMSG is shown in Figure 6.

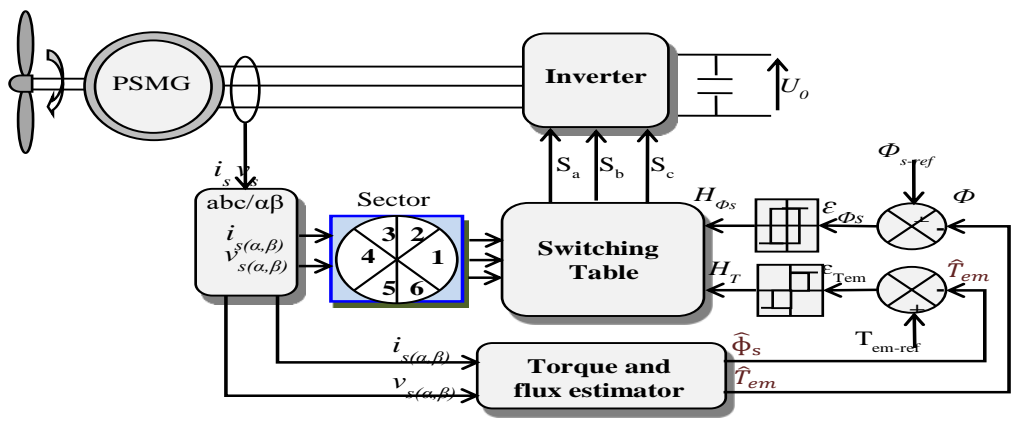

Figure 6. Structure of the direct torque control of the PMSG

\subsubsection{Estimation of Stator Flux and Electromagnetic Torque}

The performance of the control system depends on the accuracy in the estimation of these magnitudes. The estimation of the stator flux and electromagnetic torque requires prior knowledge of the current and stator voltage components [23-24].

The computation of the flux components of the PMSG in the reference frame $(\alpha, \beta)$ are determined by:

$\left\{\begin{array}{l}\widehat{\Phi}_{s \alpha}=\int_{0}^{t}\left(V_{s \alpha}-R_{s} I_{s \alpha}\right) d t \\ \widehat{\Phi}_{s \beta}=\int_{0}^{t}\left(V_{s \beta}-R_{s} I_{s \beta}\right) d t\end{array}\right.$

With: $\vec{\phi}_{s}=\widehat{\phi}_{s \alpha}+j \cdot \widehat{\phi}_{s \beta}$

The modulus of the stator flux is written:

$\widehat{\Phi}_{s}=\sqrt{\widehat{\phi}_{s \alpha}^{2}+\widehat{\Phi}_{s \beta}^{2}}$

The sector in which the vector $\bar{\phi}_{\mathrm{s}}$ is located is determined from the components $\widehat{\phi}_{\mathrm{s} \alpha}$ and $\widehat{\phi}_{\mathrm{s} \beta}$.

$\Theta=\operatorname{Arctg} \frac{\widehat{\Phi}_{s \beta}}{\widehat{\Phi}_{s \alpha}}$

Once the two flux components are determined, the electromagnetic torque can be estimated by the following equation:

$$
\widehat{T}_{e m}=\frac{3}{2} p \cdot\left(\widehat{\phi}_{s \alpha} I_{s \beta}+\widehat{\phi}_{s \beta} I_{S \alpha}\right)
$$




\subsubsection{Elaboration of Flux and Torque Regulators}

A stator flux regulator has been used to maintain the extremity of the flux vector $\phi s$ in a circular ring. The difference $\varepsilon \phi$ between the reference flux $\phi$ s-ref and the estimated flux $\widehat{\phi}_{s}$ is introduced into a twolevel hysteresis comparator $(0,1)$ as shown in Figure 7 . The hysteresis comparator generates at its output the values: $\mathrm{H} \phi=1$ to increase the flux and $\mathrm{H} \phi=0$ to reduce the flux.

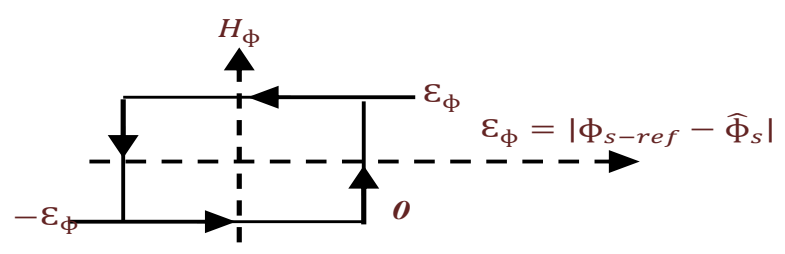

Figure 7. Two-level hysteresis regulator

The electromagnetic torque regulator is used to control the machine in both directions of rotation, generating either a positive torque, or negative torque. By applying the difference $\varepsilon$ Tem between the reference torque Tem-ref and the estimated torque $\widehat{T}_{e m}$ in hysteresis comparator with three-level, this one generates the values: HTem $=1$ to increase the torque, HTem $=-1$ to reduce it and HTem $=0$ to keep it constant in the band Figure 8.

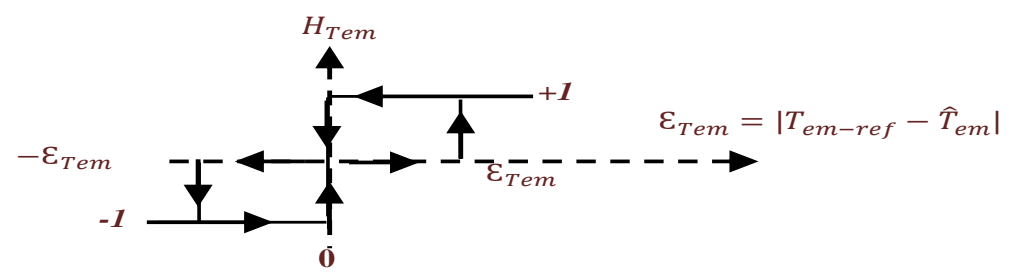

Figure 8. Three-level hysteresis regulator

\subsubsection{Elaboration of the Switching Table}

The choice of the inverter state is made in a switching table elaborated as a function of the variables state (Hфand HTem) at the output of flux regulators and the electromagnetic torque, as well as the sector $\mathrm{Si}$ giving the information on the position of the flux vector. Table 1 is presented in the following form:

\begin{tabular}{cllccccc}
\multicolumn{7}{c}{ Table 1. Switching Table } \\
\hline$H_{\phi s}$ & $H_{T e m}$ & $S_{1}$ & $S_{2}$ & $S_{3}$ & $S_{4}$ & $S_{5}$ & $S_{6}$ \\
\hline \multirow{3}{*}{1} & 1 & $V_{2}$ & $V_{3}$ & $V_{4}$ & $V_{5}$ & $V_{6}$ & $V_{I}$ \\
& 0 & $V_{7}$ & $V_{0}$ & $V_{7}$ & $V_{0}$ & $V_{7}$ & $V_{0}$ \\
& -1 & $V_{6}$ & $V_{1}$ & $V_{2}$ & $V_{3}$ & $V_{4}$ & $V_{5}$ \\
& 1 & $V_{3}$ & $V_{4}$ & $V_{5}$ & $V_{6}$ & $V_{1}$ & $V_{2}$ \\
0 & 0 & $V_{0}$ & $V_{7}$ & $V_{0}$ & $V_{7}$ & $V_{0}$ & $V_{7}$ \\
& -1 & $V_{5}$ & $V_{6}$ & $V_{1}$ & $V_{2}$ & $V_{3}$ & $V_{4}$ \\
\hline
\end{tabular}

\subsection{Application Of DPC to the Grid-Side Converter}

The purpose of Direct Power Control (DPC) is to directly control the active and reactive power from the machine to the grid. This control is similar to that of DTC, it consists in selecting a sequence of switching controls $(\mathrm{Sa}, \mathrm{Sb}, \mathrm{Sc})$ of the semiconductors constituting GSC, this choice is based on the use of two hysteresis comparators for the errors of instantaneous active and reactive powers Pg and Qg. The outputs of these regulators with the sector where the position of the grid voltage vector is located,constitute the inputs of a switching table which in turn determines the switching state of the switches, the active power reference is obtained from the DC bus voltage regulator. Figure 9 illustrates the DPC applied to grid-side converter. 


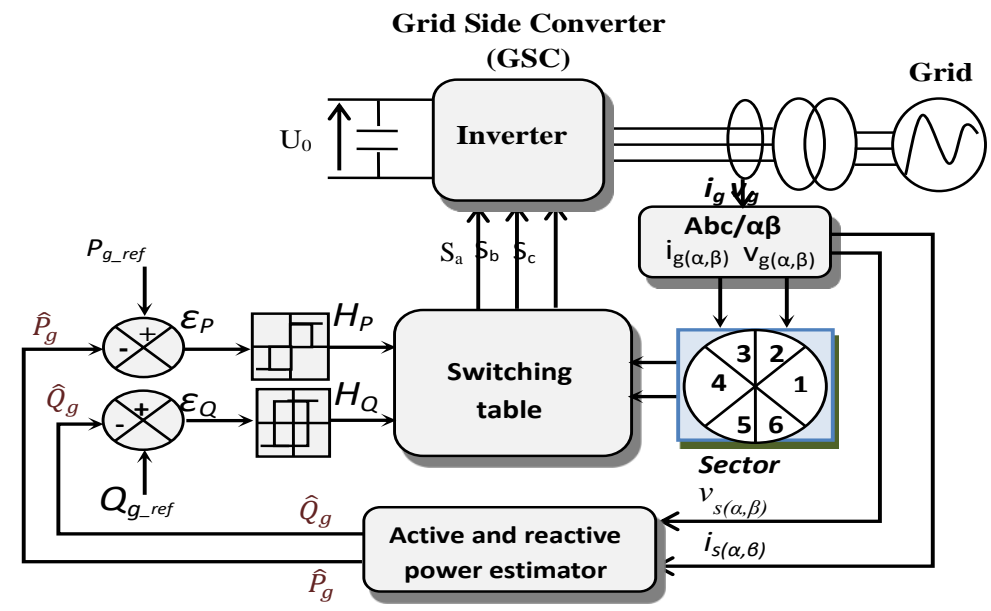

Figure 9. General schematic of the DPC applied to grid-side converter

Estimation is a very important step in achieving good system performance. Hence the active and reactive powers are estimated from the measured voltage and current, they are given by the following equations:

$$
\begin{aligned}
& P_{g}=\frac{3}{2}\left(v_{g \alpha} i_{g \alpha}+v_{g \beta} v_{g \beta}\right) \\
& Q_{g}=\frac{3}{2}\left(v_{g \alpha} i_{g \beta}-v_{g \beta} i_{g \alpha}\right)
\end{aligned}
$$

The position of the grid voltage vector that determines the sector $\mathrm{Si}$ is defined by the following equation:

$$
\theta=\operatorname{Arctg} \frac{v_{g \beta}}{v_{g \alpha}}
$$

Similarly for DTC, a three-level hysteresis regulator is used to control active power. While, a twolevel hysteresis regulator is used to control the reactive power. The outputs of these regulators with the information of the sector Si form a selection table which serves to switch the switches of the inverter which is presented by the Table 2 .

Table 2. Table of Voltage Vector Selection

\begin{tabular}{cllccccc}
\hline$H_{Q g}$ & $H_{P g}$ & $S_{1}$ & $S_{2}$ & $S_{3}$ & $S_{4}$ & $S_{5}$ & $S_{6}$ \\
\hline \multirow{4}{*}{1} & 1 & $V_{5}$ & $V_{6}$ & $V_{1}$ & $V_{2}$ & $V_{3}$ & $V_{4}$ \\
& 0 & $V_{7}$ & $V_{0}$ & $V_{7}$ & $V_{0}$ & $V_{7}$ & $V_{0}$ \\
& -1 & $V_{3}$ & $V_{4}$ & $V_{5}$ & $V_{6}$ & $V_{1}$ & $V_{2}$ \\
0 & 1 & $V_{6}$ & $V_{1}$ & $V_{2}$ & $V_{3}$ & $V_{4}$ & $V_{5}$ \\
& 0 & $V_{0}$ & $V_{7}$ & $V_{0}$ & $V_{7}$ & $V_{0}$ & $V_{7}$ \\
& -1 & $V_{2}$ & $V_{3}$ & $V_{4}$ & $V_{5}$ & $V_{6}$ & $V_{1}$ \\
\hline
\end{tabular}

\section{SIMULATION RESULTS}

To study the performance and stability of WECS systems, the numerical simulations were carried out for the low power system with a real wind profile of the coastal zone of the Kingdom of Morocco Essaouira city. The following Figures show the results obtained using the Matlab /Simulink environment.

The simulation results show that the control used has very good dynamic and static performance. The PMSG based control system was tested for the assumed variation in wind speed for 30 seconds shown in Figures 10 and 11 . The nominal wind speed was adopted equal to $8 \mathrm{~m} / \mathrm{s}$.

Figure 12 shows the forms of measured and estimated wind speed, the latter is precisely adjusted to the forms of the measured speed, which shows that the algorithm of the speed control is ensured. Moreover, the forms of power illustrated in Figure 13 show that the mechanical power is proportional to the wind speed. 
Figures 14 and 15 respectively show the variation of the ratio of the specific speed $\lambda$ and the power coefficient $\mathrm{Cp}$. We verify that the values of the specific speed and the power coefficient are almost equal to their optimal values.

Figure 16 shows the response of the electromagnetic torque Tem of PMSG during the wind speed variation, it is proportional to the speed of the wind. Figure 17 shows the shape of the DC bus voltage U0. The instantaneous values of this voltage are quite constant; it perfectly follows its reference value with a response time equal to $800 \mathrm{~ms}$.

The Figures 18 and 19 show that the instantaneous active and reactive powers, delivered to the alternating grid, follow its reference values. In addition, the reactive power is zero which causes a unit power factor and the only active power generated by WECS is fully supplied to the grid. The stator current components presented in Figures 20 and 21 are sinusoidal gaits with amplitudes varying according to wind speed and its frequency remains at a value of $50 \mathrm{~Hz}$.

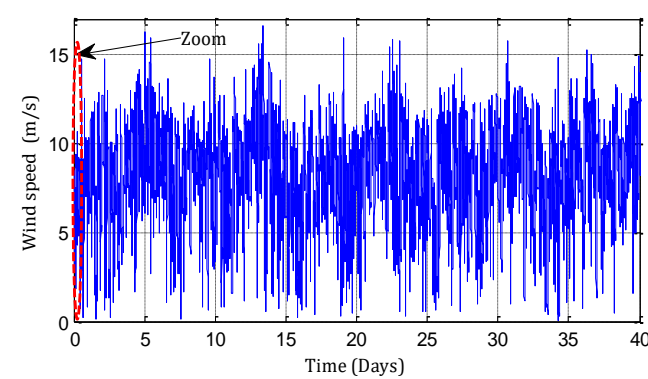

Figure 10. Variable wind profile of the Essaouira-Morocco city

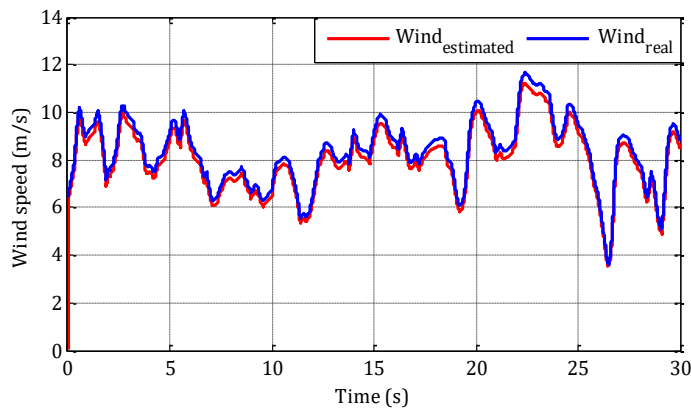

Figure 12. Wind speed
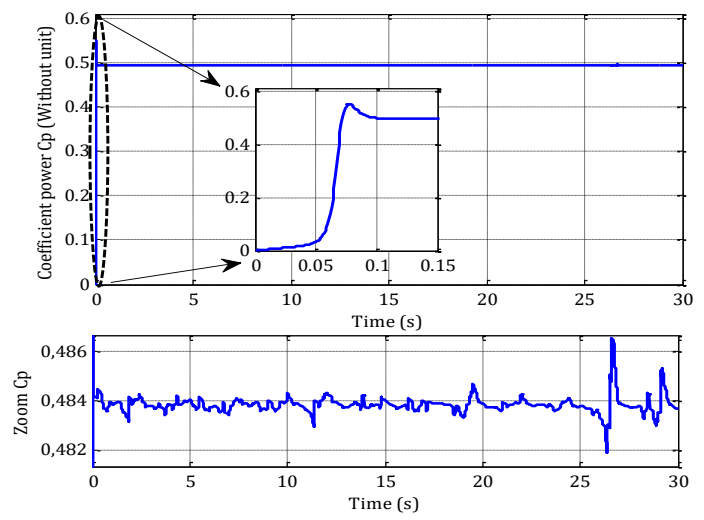

Figure 14. Power coefficient

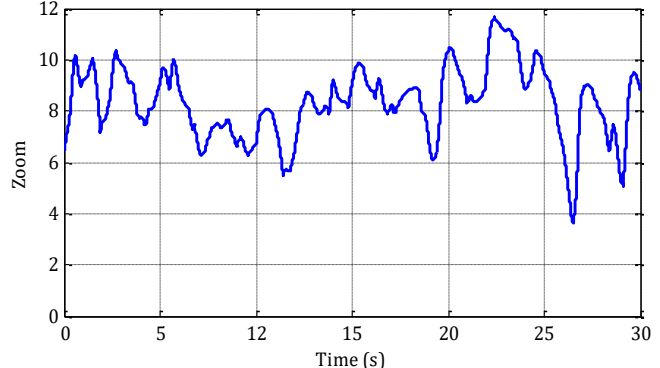

Figure 11. Wind profile zoom

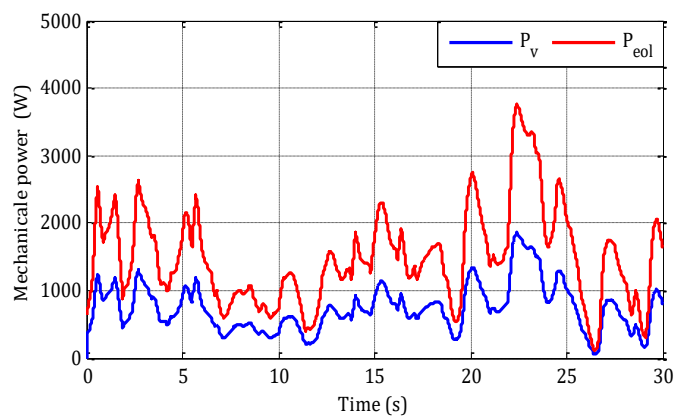

Figure 13. Mechanical power
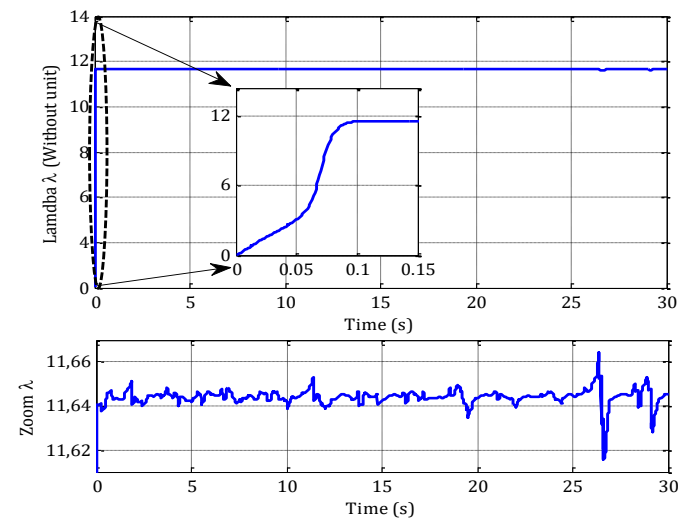

Figure 15. tip-speed ratio 


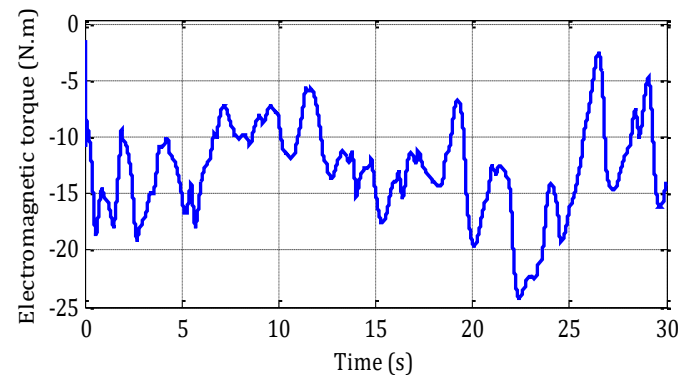

Figure 16. Electromagnetic torque

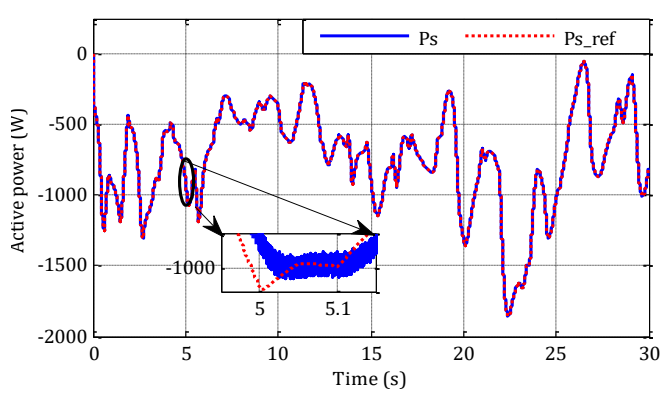

Figure 18. Active power

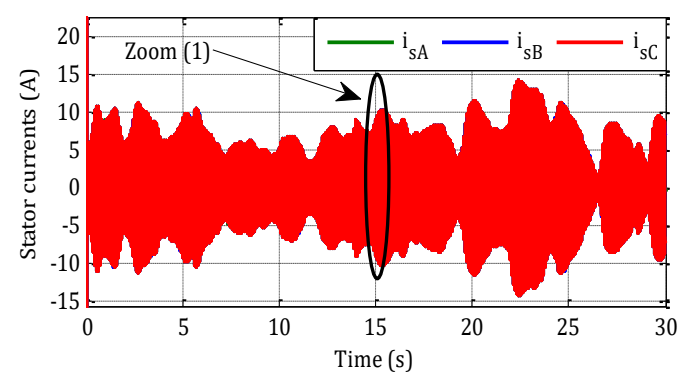

Figure 20. stator currents

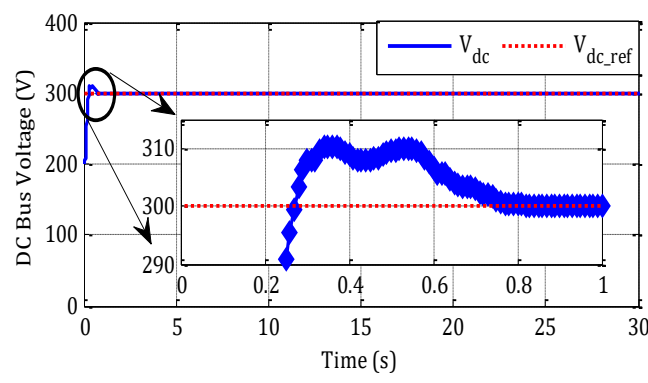

Figure 17. DC bus voltage

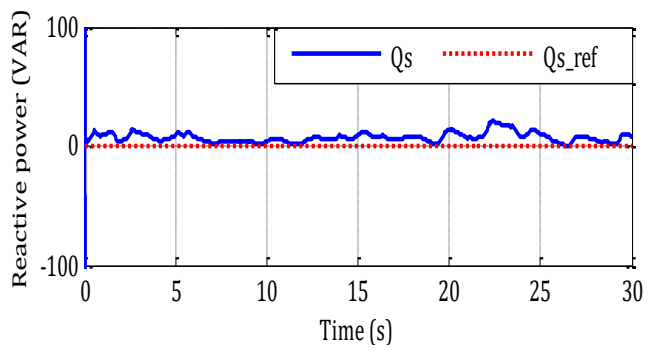

Figure 19. Reactive power

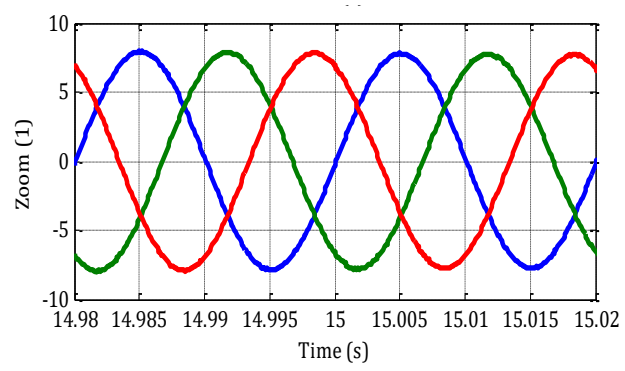

Figure 21. Zoom of stator currents

\section{CONCLUCION}

This article discusses a control strategy for a wind system based on PMSG with variable wind speed. After modeling the wind energy conversion system with PMSG-Converters, the direct control structures were taken into account. The control algorithm for the machine-side converter is based on the direct torque control. For the grid-side converter the Direct Power Control method has been applied. We adopted a variable wind of the Essaouira-Morocco city to evaluate the performance of the system in real case. The main conclusions of this study are:

a. The performance of the control applied in real wind conditions remains reliable.

b. Operation with a unit power factor was ensured.

c. Power is always required with good operation.

The simulation results show that direct controls provide good performance to the WECS system. The effectiveness of this control can be asserted from the results found in this article. And as a perspective our proposed order will be implemented on the dSPACE DS1104 board to confirm the results obtained by this study. 


\section{REFERENCES}

[1] E. Haque, and al.," A Novel Control Strategy for a Variable-Speed Wind Turbine With a Permanent Magnet Synchronous Generator," IEEE Transactions on Industry Applications, Vol. 46 , Issue: 1, Jan.-feb. 2010.

[2] F. Tinazzi, and al.,"Torque Estimation in High-Efficency IPM Synchronous Motor Drives", IEEE Transactions on Energy Conversion, Vol. 30 , Issue: 3 , pp.142-147, Sep. 2015.

[3] S. Muller, and al., "Doubly fed induction generator systems for wind turbines", IEEE Industry Applications Magazine, Vol. 8, Issue: 3, pp. 26-33, June 2002.

[4] C. Busca,, and al., "Control of Permanent Magnet SynchronousGenerator for Large Wind Turbines," IEEE International Symposium on Industrial Electronics, 2010, pp. 3871-3876.

[5] M. Taoussi, and al., "The Fuzzy Control for Rotor Flux Orientation of the double-fed asynchronous generator Drive", International Journal of Computers \& Technology, Vol.13, №.08, pp. 4707-4722, Mai.2013.

[6] D. Hammoumi, and al., "Control wind energy system to variable speed based on the permanent magnet synchronous generator", Processing IEEE Xplore, pp. 1-6, Oct. 2017.

[7] B. Bossoufi, and al.," FPGA-Based Implementation Nonlinear Backstepping Controlof a PMSM Drive," International Journal of Power Electronics and Drive System (IJPEDS), Vol.4, No.1, pp. 12 23, March 2014.

[8] M. Taoussi, and al., "Low-Speed Sensorless Control for Wind Turbine System", WSEAS Transactions on Systems and Control, Vol.12, pp. 405-417, Dec. 2017.

[9] M. Taoussi, and al., "Comparative study between Backstepping adaptive and Field-oriented control of the DFIG applied to wind turbines", Processing IEEE Xplore, pp. 1-6, Oct. 2017.

[10] M. Taoussi, and al., "Speed variable adaptive Backstepping control of the doubly-fed induction machine drive", International Journal of Automation and Control, Vol.10, $\mathrm{N}^{\circ} .01$, pp. 12-33, 2016.

[11] M. Taoussi, and al., "Speed Backstepping Control of The Double-Fed Induction Machine Drive“, Journal of Theoretical \& Applied Information Technology, Vol.74, №.02, pp. 189-199, Avril 2015.

[12] B. Bossoufi, and al., "Observer backstepping control of DFIG-Generators for wind turbines variable-speed: FPGAbased implementation”, Renewable Energy, Vol.81, pp. 903-917, Sep. 2015.

[13] Y. El Mourabit, and al., "DTC-SVM Control for Permanent Magnet Synchronous Generator based Variable Speed Wind Turbine", International Journal of Power Electronics and Drive Systems (IJPEDS), Vol.8, Issue:4, pp. 1732-1743, Dec. 2017.

[14] N. El Ouanjli, and al., "Contribution to the performance improvement of Doubly Fed Induction Machine functioning in motor mode by the DTC control," International Journal Power Electronics and Drive System (IJPEDS), Vol.8, No.3, Sept. 2017.

[15] D. Miao, and al., "Wide Speed Range Permanent Magnet SynchronousGenerator Design for a DC Power System," Chinese Journal of Electrical Engineering, Vol.3, No.1, June 2017.

[16] N. El Ouanjli,and al.,"Modern improvement techniques of direct torque control for induction motor drives-a review", Protection and Control of Modern Power Systems, vol.7, (2019).

[17] N. El Ouanjli, and al., "Direct Torque Control Strategy Based on Fuzzy Logic Controller for a Doubly Fed Induction Motor", Processing IOPscience, Vol. 161, June 2018.

[18] B. Bossoufi, and al., "Backstepping control of DFIG generators for wide-range variable-speed wind turbines", International Journal of Automation and Control, Vol.08, $\mathrm{N}^{\circ} .02$, pp. 122-140, Jan. 2014.

[19] N. El Ouanjli, and al., "A comparative study between FOC and DTC controls of the Doubly Fed Induction Motor (DFIM) ", Processing IEEE Xplore, Jan. 2018.

[20] B. Bossoufi, and al., "Backstepping Adaptive Control of DFIG-Generators for Variable-Speed Wind Turbines", International Journal of Computers \& Technology, Vol.12, №.07, pp. 3719-3733, Fev. 2014.

[21] B.Bossoufi, and al., "Robust Adaptive Backstepping control approach of DFIG Generators for Wind Turbines Variable-Speed", Processing IEEE Xplore, 16 March 2015.

[22] N. El Ouanjli, and al.,"High Performance Direct Torque Control of Doubly Fed Induction Motor using Fuzzy Logic. Gazi University Journal of Science, Vol.31, Issue: 2, pp. 532-542, 2018.

[23] N. El Ouanjli, and al., "A comparative study between FOC and DTC controls of the Doubly Fed Induction Motor (DFIM) ”, Processing IEEE Xplore, pp. 1-6, Jan. 2018.

[24] V. T. Luong, and al., Advanced Control Strategy of Back-to-Back PWMConverters in PMSG Wind Power System," Power Engineering And Electrical Engineering, Vol. 13, Issue : 2, pp. 81-95, June 2015.

\section{NOMENCLATURE}

\begin{tabular}{|ll|ll|}
\hline$V_{s(\alpha, \beta)}$ & $: \alpha-\beta$ axis stator voltage. & $P_{g}$ & $:$ Active grid power. \\
$i_{s(\alpha, \beta)}$ & $: \alpha-\beta$ axis stator current. & $Q_{g}$ & $:$ Reactive grid power. \\
$\varphi_{s(\alpha, \beta)}$ & $: \alpha-\beta$ axis stator flux. & $U_{0}$ & $:$ DC-link voltage. \\
$\psi_{f}$ & $:$ Magnetic flux. & $P_{e o l}$ & $:$ Mechanical power. \\
$\Omega$ & $:$ Mechanical turbine speed. & $T_{e o l}$ & $:$ Turbine torque. \\
$\omega$ & $:$ Electric pulsation. & $C_{p}$ & $:$ Power coefficient. \\
$R_{s}$ & $:$ Stator resistance. & $\lambda$ & $:$ tip-speed ratio. \\
$L_{s}$ & $:$ Stator inductance. & $\beta$ & $:$ Pitch angle \\
$J$ & $:$ Total moment of inertia. & $R_{t}$ & $:$ Turbine radius. \\
$f$ & $:$ Coefficient of viscous friction. & $V_{v}$ & $:$ Wind speed \\
$p$ & $:$ Number of poles pairs. & $P_{v}$ & $:$ Wind power. \\
$T_{e m}$ & $:$ Electromagnetic torque. & & \\
\hline
\end{tabular}




\section{APPENDIX}

\begin{tabular}{cccc}
\hline \multicolumn{2}{c}{ Parameters of the PMSG } & \multicolumn{2}{c}{ Parameters of the turbine } \\
\hline Rated Power & $\mathrm{P}=2 \mathrm{Kw}$ & Blade radius & $\mathrm{R}=2 \mathrm{~m}$ \\
Rated Voltage & $\mathrm{Vs}=220 / 380 \mathrm{~V}$ & Number of blades & 3 \\
Rated speed & $\mathrm{N}=1500 \mathrm{rpm}$ & Moment of inertia & $\mathrm{J}_{\mathrm{t}}=0.089 \mathrm{Kg} . \mathrm{m}^{2}$ \\
Stator Resistance & $\mathrm{Rs}=2.6 \Omega$ & friction coefficient & $\mathrm{f}=0,0003035 \mathrm{~N} . \mathrm{m} . \mathrm{s} / \mathrm{rad}$ \\
Inductances synchrones & $\mathrm{Ld}=43 \mathrm{mH}$ & Rated wind speed & $\mathrm{V}=15 \mathrm{~m} / \mathrm{s}$ \\
Flux efficace & $\mathrm{Lq}=43 \mathrm{p} . \mathrm{u}$ & Masse volumique de l'air & $\rho=1.225 \mathrm{~kg} / \mathrm{m} 3$ \\
Number of pole pairs & $\psi \mathrm{f}=0.178 \mathrm{~Wb}$ & & \\
Moment of Inertia & $\mathrm{p}=2$ & & \\
\hline
\end{tabular}

